\title{
EXTENSÃO UNIVERSITÁRIA: ENTRE O CONTINUISMO E A UTOPIA
}

\author{
Eros Marion Mussoi \\ Universidade Federal de Santa Catarina \\ eros.mussoi@ufsc.br \\ Lucia Helena Correa Lenzi \\ Universidade Federal de Santa Catarina \\ lucia.lenzi@ufsc.br
}

\begin{abstract}
Resumo
Problematizamos a extensão universitária da Universidade Federal de Santa Catarina, investigando suas inter-relações com a sociedade. Trabalhamos com dados recolhidos em cerca de 18.000 projetos de extensão da UFSC, de 2008 a 2013. Verificamos expressiva concentração da Extensão da UFSC na Grande Florianópolis ( $84 \%$ dos projetos) e, nessa região, predominância absoluta de Florianópolis ( $98 \%$ dos projetos). Em termos socioeconômicos, constatamos que os municípios com menor IDH do Estado não são priorizados nas ações de extensão. A partir dessas constatações, caracterizamos a necessidade de uma atuação interdisciplinar e intersetorial mais consistente, a partir de uma lógica territorial. Propomos a definição de territórios-foco onde todas as ações de extensão da Universidade estejam perfeitamente integradas, tanto em planejamento quanto em execução/monitoramento. Buscamos, portanto, assumir a perspectiva de um processo multiautoral, demarcando a necessidade também de a universidade articular-se com organismos de políticas públicas municipais, estaduais e federal, para melhor andamento e continuidade dos projetos/ações de extensão universitária.
\end{abstract}

Palavras-chave: Extensão universitária. Território. Gestão social.

\section{UNIVERSITY EXTENSION: BETWEEN CONSERVATISM AND UTOPIA}

\begin{abstract}
We discuss university extension at the Federal University of Santa Catarina, investigating its interrelations with society. We work with data collected from about 18,000 extension projects of UFSC, from 2008 to 2013 . We could notice a significant concentration of the extension projects in the metropolitan region of Greater Florianópolis ( $84 \%$ of the projects) and, within this region, absolute predominance of Florianópolis ( $98 \%$ of projects). In socioeconomic terms, it appears that the towns with the lowest HDI in Santa Catarina are not prioritized by the extension actions. These findings suggest the need for a more consistent interdisciplinary and intersectoral action, in a territorial logic. We propose that focus territories are defined where all the extension actions of the University should be fully integrated, both in terms of planning and implementation/monitoring. We thus seek to assume the perspective of a multi-actor process, pointing out the need for the university to articulate with local, state and federal public policy organizations, in order to attain a smooth running and continuity of the projects/actions of university extension.
\end{abstract}

Keywords: University extension. Territory. Social management.

\section{EXTENSIÓN UNIVERSITARIA: ENTRE EL CONSERVADURISMO Y LA UTOPÍA}

\section{Resumen}

Se discute la extensión universitaria de la Universidad Federal de Santa Catarina, investigando sus interrelaciones con la sociedad. Trabajamos con los datos recogidos de cerca de 18.000 proyectos de extensión de la UFSC, de 2008 a 2013. Podemos notar una concentración significativa de los proyectos de extensión en la región metropolitana de la Gran Florianópolis ( $84 \%$ de los proyectos) y, dentro de esta región, predominio absoluto de Florianópolis ( $98 \%$ de los 
proyectos). En términos socioeconómicos, parece que las ciudades con el IDH más bajo en Santa Catarina no se priorizan en las acciones de extensión. Estos hallazgos sugieren la necesidad de una acción interdisciplinaria e intersectorial más coherente, en una lógica territorial. Proponemos que se definan territorios de enfoque en que todos las acciones de extensión de la Universidad deban ser plenamente integrados, tanto en términos de planificación cuanto de ejecución /supervisión. Por lo tanto buscamos asumir la perspectiva de un proceso multi-actoral, señalando la necesidad de que la universidad se articule con organizaciones políticas públicas locales, estatales y federales, con el fin de lograr un buen funcionamiento y la continuidad de los proyectos / acciones de extensión universitaria.

Palabras clave: Extensión Universitaria. Territorio. Gestión social. 


\section{INTRODUÇÃO}

Inicialmente, os autores esclarecem que o termo "utopia" é utilizado no sentido dado por Eduardo Galeano, já que, na esteira das palavras deste autor é possível compreender que "a utopia é algo que a gente se aproxima dela um passo e ela se afasta dois". É nessa perspectiva que tomamos a utopia, não como um sonho inatingível, mas sim como algo a ser buscado sempre.

A Extensão Universitária, antes um tanto esquecida entre as diversas dimensões das atribuições da Universidade, principalmente pela importância assumida pelos segmentos de Pesquisa e Ensino, hoje propõe para si um novo e necessário debate.

Este esquecimento histórico trouxe consequências marcantes dentro dos Projetos Político-Pedagógicos das entidades de ensino superior. O primeiro deles, já mencionado, foi colocar ordens de hierarquização de importância, priorizando as dimensões da Pesquisa e do Ensino, muitas vezes entendidos como segmentos autossuficientes.

Este equivocado entendimento, de independência relativa entre as três dimensões básicas da função social da Universidade, foi "resolvido" por um conjunto de ações relativamente à Extensão Universitária que trouxeram vícios de função que persistem e provocam uma perspectiva de continuísmo, muitas vezes afastando a Universidade da Sociedade que a mantém e que a ela deveria conduzir seus objetivos e ações.

Desta forma, a Universidade "faz a Extensão que quer fazer" e não a que a Sociedade precisa. Se isso tem sentido, pode-se afirmar que, agindo desta forma, a Universidade está longe de exercitar seu total potencial de intervenção junto à Sociedade para transformá-la (em benefício dela própria). Pela presente compreensão, este conjunto de ações muitas vezes tem características isoladas, disciplinares, individualistas e voluntaristas de docentes e discentes, que - muitas vezes, na melhor das intenções - atuam a partir de projetos pessoais ou de grupos disciplinares.

Isto não quer dizer que não se encontrem projetos que já busquem a integração intradisciplinar (e mesmo interdisciplinar) e uma busca de ações a partir dos interesses da Sociedade, principalmente por intervenção e demandas de grupos sociais específicos e bem articulados politicamente. Mas, efetivamente, não representam o que faz̧er extensionista da Universidade. Não representam uma clara postura político-institucional e transformadora.

Também não existe clareza de atuações consistentes e programadas interdisciplinarmente em territórios geográficos comuns, o que indica uma dispersão enorme de esforços, ao contrário de uma desejada ação integrada e integradora, que traria muito maior consistência em termos de retorno socioambiental e econômico, tanto para a Sociedade quanto para a Universidade em suas três dimensões básicas. 
Extensão universitária: entre o continuismo e a utopia

A intenção deste texto é ser um instrumento provocativo... para poder transformar e superar o continuísmo. O problema está posto: é preciso, de maneira consistente, transformar as ações da Universidade, seja elas de Pesquisa, Ensino ou Extensão. Esta última dimensão é foco deste trabalho, sem desmerecer ou esquecer as outras duas - ao contrário, percebendo-as como perfeitamente integradas e complementares.

Uma das questões fundamentais para analisarmos a inter-relação entre as três dimensões básicas da Universidade poderia ser demarcada perguntando: a Extensão hoje realizada é capaz de trazer modificações no Ensino, tanto no seu conteúdo quanto na sua metodologia? Onde nascem os projetos de Pesquisa e Extensão Universitária de um modo geral? Nascem da análise concreta das demandas da Sociedade ou da percepção pontual dos próprios professorespesquisadores? Ou surgem ainda da replicação de pesquisas realizadas em centros de investigação internacionais ou mesmo nacionais? Estas ações, se existirem, acontecem de maneira consistente em áreas geográficas comuns? Ou são dispersas?

Por outro lado, parecem não existir dúvidas de um envolvimento comparativo muito maior de professores(as) em projetos de Extensão. No entanto, este envolvimento mais intensivo pode ser devido a três fatores básicos: 1) a intenção de realmente realizar atividades extensionistas pelo entendimento de sua importância e pela existência de políticas de maior apoio à atividade; 2 ) a exigência de inclusão de atividades de Extensão nos planos de trabalho (PAADs - Planos de Atividades Docentes, preenchidos a cada semestre); 3) a busca de novas fontes de recursos que proporcionam montagens de equipes de trabalho com bolsas para estudantes e mesmo professores.

A hipótese que se levanta é de que projetos setorizados, disciplinares, individualizados ou mesmo aqueles que são expressão de voluntarismos militantes são de fato importantes, mas insuficientes para tratar a complexidade da integralidade referente a problemática sócioambiental-econômica e de gestão pública, tão carente nas administrações municipais e regionais (sem desconhecer a questão dos outros universos de gestão) e mesmo na gestão privada de projetos e programas.

\section{DISCUTINDO ALGUNS CONCEITOS BÁSICOS NA EXTENSÃO}

Fundamental é buscar no conceito de Desenvolvimento e em sua complexidade analítica e de intervenção base para discutir-se a importância de uma nova Extensão Universitária. Neste sentido, torna-se cada vez mais clara a insuficiência dos modelos de crescimento econômico no 
Extensão universitária: entre o continuismo e a utopia

sentido de, democraticamente, dar conta do conjunto de problemas sócio-ambientaiseconômicos e de gestão pública que assolam a Sociedade atualmente.

Este modelo de crescimento econômico foi marcante e hegemônico nas últimas seis décadas e levou para o interior da Universidade uma visão linear e unidirecional de solução de problemas mediante o uso puro e simples (e a qualquer preço) de tecnologias modernizadoras.

No entanto, a complexidade da problemática (que o próprio modelo de crescimento econômico trouxe) e suas externalidades têm mostrado a insuficiência nas respostas efetivas e têm, gradativamente, agravado mais ainda os problemas básicos originais, sejam eles relativos à inclusão social, às questões ambientais, ou à gestão pública em seu viés de participação democrática de cidadania.

Isto nos faz refletir que desenvolver a humanidade nos seres humanos, contribuir para seu amadurecimento como pessoas e como cidadãos, é a razão fundamental da Universidade. $\mathrm{Ou}$ seja, as disciplinas acadêmicas não têm "necessariamente como objetivo unicamente transmitir um saber científico ou uma competência prática, mas estruturar uma personalidade segundo um certo ideal civilizatório [...]” (JAPIASSU; MARCONDES, 2001 p. 123). Como observa o filósofo Joseph J. Kockelmans,

[...] parece-me que a universidade deve preparar seus estudantes para essa busca pela integração e pela unidade. Isso pode ser feito assegurando-se de que todos os estudantes são introduzidos de maneira apropriada tanto nas ciências quanto nas humanidades. Quando, mais tarde, na vida real da sociedade, sérios problemas sociais tiverem de ser resolvidos, nossos graduados deverão estar preparados para sugerir soluções cientificamente realizáveis e humanisticamente respeitáveis (KOCKELMANS, 1979, p. 44).

Ora, é justamente a dimensão da Extensão Universitária que lida mais diretamente com a questão da complexidade, na medida em que atua em realidades extremamente complexas, como é a efetiva realidade social das comunidades rurais e urbanas e seu intricado tecido de relações (no sentido sócio-econômico-ambiental e político-organizativo).

O desafio que se coloca leva-nos, necessariamente, a refletir mais uma vez sobre a formação (e atuação) interdisciplinar, que envolve, conjuntamente, as Ciências Naturais, as Ciências Humanas e as Humanidades e, logicamente, a pensar em projetos e ações de Extensão Universitária que sejam efetivamente interdisciplinares e intersetoriais. Ou seja, faz-se necessário propor ações que advenham de uma interação prolongada e coordenada entre disciplinas acadêmicas para o tratamento de um tema ou a resolução de um problema complexo, levando à integração dos diferentes discursos e à criação de uma linguagem comum ou de um quadro conceitual comum, formando pontes entre as estruturas disciplinares. Com isso, pode-se chegar a 
Extensão universitária: entre o continuismo e a utopia

formular uma metodologia comum, transcendendo ou na interface das epistemologias de diferentes disciplinas.

Segundo Raynaut (2011), a interdisciplinaridade se caracteriza por gerar constante dúvida e estar em permanente construção. $O$ autor afirma que a interdisciplinaridade implica, mais fundamentalmente, na adoção de uma nova postura intelectual em face da natureza complexa dos problemas com os quais o cientista contemporâneo se confronta.

Somente uma ação interdisciplinar perfeitamente integrada e participativa, desde a análise e planejamento até a execução, monitoramento e avaliação dos projetos de Extensão Universitária, pode levar à formação do pensamento crítico-propositivo. Desta forma, estar-se-á contribuindo com novas perspectivas profissionais e atuando muito mais em função concreta das necessidades da Sociedade.

\section{UMA APROXIMAÇÃO À REALIDADE ATUAL DA “EXTENSÃO UNIVERSITÁRIA”}

A realidade, a seguir trabalhada, trata de uma análise preliminar dos projetos de Extensão Universitária da Universidade Federal de Santa Catarina, no período de 2008 a 2013. Como mencionado, esses dados e suas análises preliminares, apresentados a seguir, já dão claros indicativos da necessária integração interdisciplinar e intersetorial entre os projetos de extensão.

\section{a) Levantamento da Forma de Extensão praticada}

No sentido de perceber os tipos de Extensão Universitária realizados, efetuou-se um levantamento e análise a partir da variável "forma de extensão".

Este levantamento objetivou conhecer, descrever e classificar os projetos de extensão da universidade. De imediato, é possível, a partir destes resultados, observar a falta de clareza e diversidade de entendimento sobre o que seja um projeto de extensão, pois é no mínimo questionável que realmente sejam extensão universitária ações como participação em bancas, participação em eventos, publicações, prestação de serviços, etc. Também se pode observar que alguns dados são muito subjetivos e não trazem informações da forma de extensão do projeto cadastrado. Por exemplo, foram classificados como forma de extensão "programa", "projeto", “evento”, sem caracterizar sua ação específica (Figura 1).

\footnotetext{
1 Todos dados trabalhados a seguir foram obtidos a partir de registros armazenados na SETIC- Superintendência de Governança Eletrônica e Tecnologia da Informação e Comunicação da UFSC, referindo-se ao período de 2008 ao primeiro semestre de 2013 inclusive. Esses dados são abastecidos pelos projetos elaborados pelos professores e aprovados nos diversos Departamentos de Ensino da Universidade.
} 


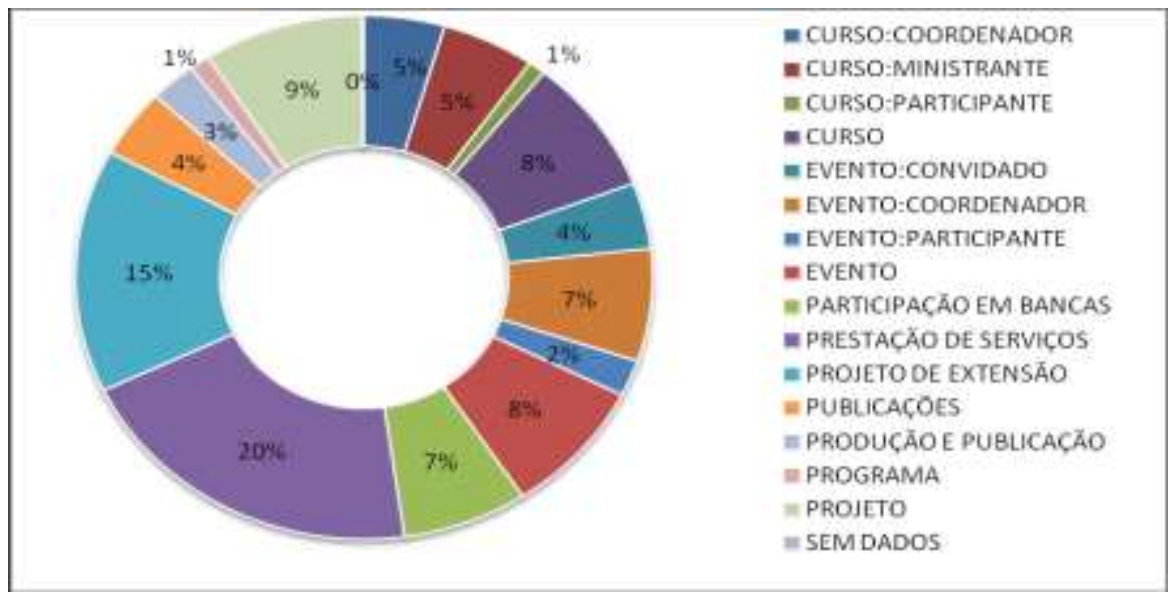

Figura 1 - Percentual das diferentes formas de extensão presentes no cadastro de projetos de extensão da UFSC - 2008 a 2013

Fonte: Setic/UFSC, 2015.

Como é possível verificar na figura acima, a forma mais relatada de extensão trata-se de "prestação de serviços", com 3.727 eventos, seguindo-se de "projetos de extensão", com 2.776 eventos. Surpreende que 1.302 eventos como "participação em bancas" sejam relatados como “extensão universitária”.

\section{b) Levantamento dos Projetos de Extensão relacionados às Mesorregiões do Estado de}

\section{Santa Catarina}

É importante informar, inicialmente, que, durante o levantamento da "variável mesorregião", foram constatados alguns erros na classificação das mesorregiões de alguns municípios. Um dos erros observados foi a falta da mesorregião Serrana (IBGE, 2009), sendo que os municípios pertencentes a ela estavam listados na mesorregião do Oeste Catarinense. Assim, primeiramente, os erros foram corrigidos, para posterior reagrupamento dos dados.

A classe 'outros' é constituída por projetos realizados em outros estados ou países, ou por projetos realizados em mais de uma cidade (de um mesmo estado/mesorregião ou não) (Figura 2). 


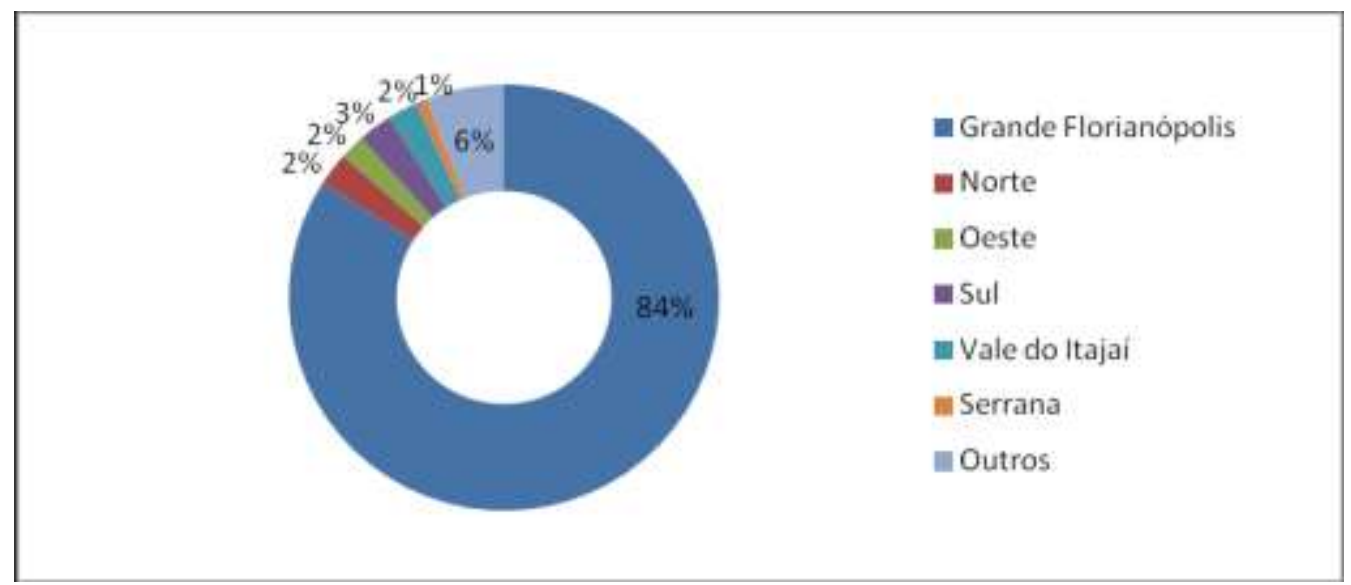

Figura 2 - Percentual das mesorregiões onde os projetos de extensão da UFSC foram executados Fonte: Setic/UFSC, 2015.

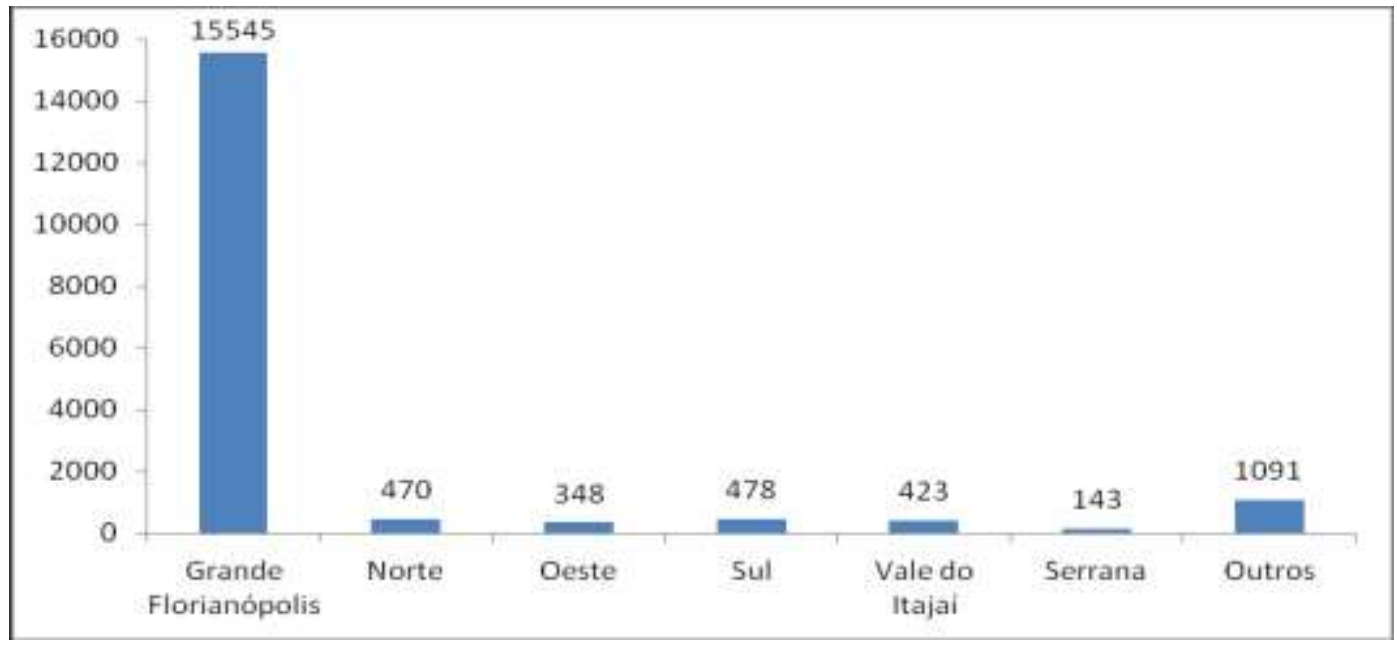

Figura 3 - Número de projetos de extensão da UFSC realizados em diferentes mesorregiões - 2008 a 2013 Fonte: Setic/UFSC, 2015.

Pelas Figuras 2 e 3, constata-se uma expressiva atuação da Extensão da UFSC na Grande Região de Florianópolis (84\%). Isso nos poderia levar a problematizar o espaço geoeducacional desta universidade, que deveria ter historicamente um compromisso com o Estado de Santa Catarina como um todo. Mesmo agora, com a implantação recente de novos Campi (Araranguá, Joinville e Curitibanos), a atuação de âmbito estadual é praticamente insignificante. Considerando-se que muitas áreas de depressão socioeconômica se localizam fora da Grande Florianópolis, pondera-se que a UFSC tem muito a contribuir com outras regiões do Estado.

Observando a expressiva atuação dos projetos de extensão na mesorregião da Grande Florianópolis, realizou-se uma segunda classificação, com a finalidade de apresentar os municípios da Grande Florianópolis em que foram realizados os projetos. Nela, pôde-se observar mais uma vez a predominância absoluta do município de Florianópolis (98,02\%), onde está 
Extensão universitária: entre o continuismo e a utopia

radicada a sede da UFSC. Se somarmos a este percentual os municípios de São José, Palhoça e Biguaçu (mais próximos e limítrofes à capital) este percentual alcança 99,66\%.

Esta notável concentração certamente é explicada pela busca de proximidade à sede da Universidade e dos Centros onde os projetos são oriundos, mas também (como hipótese) pelas formas de extensão anteriormente expostas, que podem significar um compromisso pontual e pouco estratégico.

Por outro lado, um ponto importante para reflexão é o que deveria considerar a atuação dos projetos de Extensão da UFSC relativamente ao IDH (Índice de Desenvolvimento Humano) $^{2}$ das regiões onde eles atuam.

Entre as 33 Regiões Metropolitanas do País, as quatro primeiras no ranking do IDH Municipal ficam em Santa Catarina: Grande Florianópolis, Joinville, Blumenau e Tubarão. Das dez primeiras colocadas, apenas quatro são de outros estados. Santa Catarina tem 27 cidades colocadas entre as 100 brasileiras com melhor IDH. Dos 573 municípios com nível elevado de desenvolvimento humano, 123 (mais de 20\%) são catarinenses. Florianópolis é considerada a capital com a mais alta qualidade de vida e a quarta melhor cidade do País para se viver, de acordo com a Organização das Nações Unidas (ONU).

No entanto, existe um conjunto de municípios do Estado de Santa Catarina que apresentam IDH entre as categorias de 0,67 e 0,80, que certamente representam bolsões de pobreza e/ou áreas de depressão social, que poderiam ter uma atenção muito especial de projetos de Extensão integrados para parte da UFSC, como se pode constatar no Quadro 1.

\begin{tabular}{|c|c|}
\hline IDH - Geral por município [índice] & Número de municípios \\
\hline 0,845 a 0,88 & 18 \\
\hline 0,81 a 0,845 & 76 \\
\hline 0,775 a 0,81 & 109 \\
\hline 0,74 a 0,775 & 66 \\
\hline 0,705 a 0,74 & 18 \\
\hline 0,67 a 0,705 & 6 \\
\hline
\end{tabular}

Quadro 1 - Santa Catarina - IDH-M (IDH - Médio) dos municípios catarinenses - 2000 Fonte: Borchardt, 2003)

Ou seja, dos então 293 municípios de Santa Catarina a grande maioria (199) apresentavam IDH entre 0,67 e 0,80.

A seguir, o mapa de Santa Catarina que indica os diversos municípios e seu Índice de Desenvolvimento Humano, caracterizando áreas típicas de exclusão social.

\footnotetext{
2 IDH é um indicador adotado pelo Programa para o Desenvolvimento das Nações Unidas (PNUD) para mensurar o desenvolvimento humano, levando em conta os fatores longevidade, nível educacional e renda. Ele varia de 0 a 1 . Quando está acima de 0,8 é considerado elevado. (www.pnud.org.br).
} 


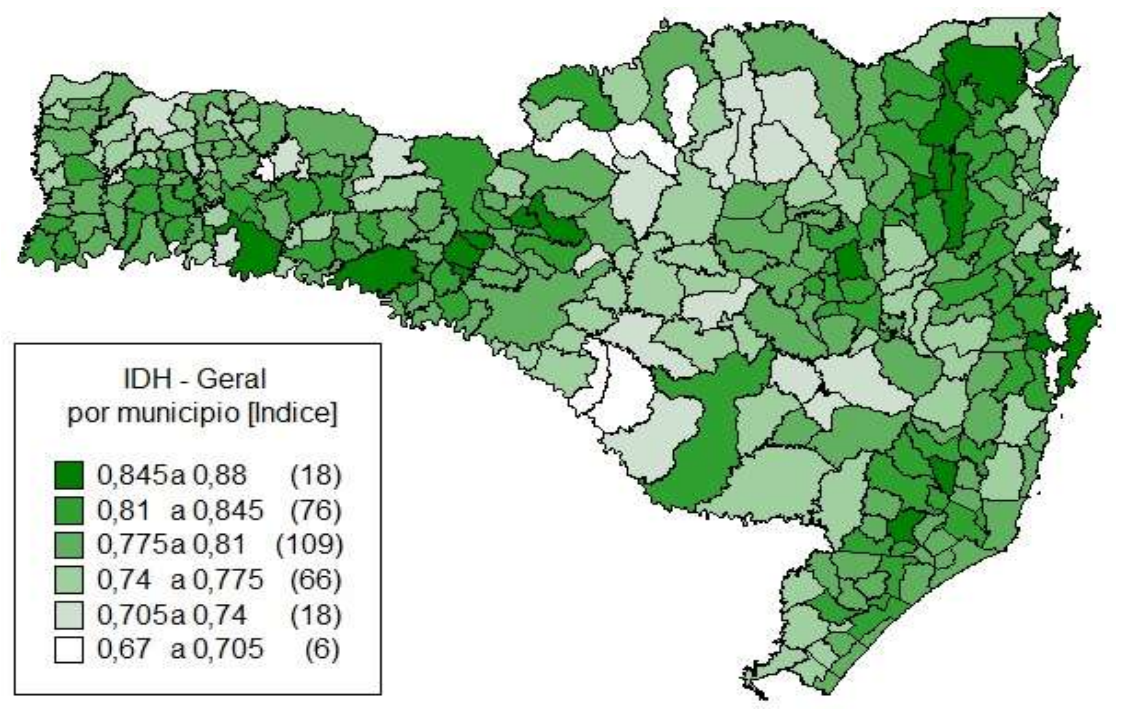

Figura 4 - IDH dos municípios catarinenses Fonte: Borchardt, 2003)

\section{c) Atuação por Mesorregiões relacionada com os Centros de Ensino da UFSC}

A Universidade Federal de Santa Catarina possui 11 Centros de Ensino, definidos por áreas setoriais de atuação ${ }^{3}$. Procurou-se observar a atuação destes Centros de Ensino com relação a Projetos de Extensão no período já mencionado, relativamente às regiões de atuação. $\mathrm{Na}$ Tabela 1, pode-se observar uma primeira classificação dos diferentes setores da universidade responsáveis pelos projetos de extensão em cada mesorregião.

\begin{tabular}{|c|c|c|c|c|c|c|c|c|c|}
\hline \multirow[b]{2}{*}{ SETORES 1} & \multicolumn{7}{|c|}{ MESORREGIÃO $^{2}$} & \multirow[b]{2}{*}{ Total } & \multirow[b]{2}{*}{$\%$} \\
\hline & $\begin{array}{l}\text { Grande } \\
\text { Fpolis }\end{array}$ & Norte & $\begin{array}{c}\text { Vale do } \\
\text { Itajaí }\end{array}$ & Oeste & Serrana & Sul & Outros & & \\
\hline Outros Campi ${ }^{3}$ & 55 & 145 & 3 & 2 & 68 & 153 & 25 & 451 & 2,44 \\
\hline Centros & 14944 & 321 & 410 & 344 & 74 & 303 & 984 & 17380 & 93,96 \\
\hline Colégio de Aplicação & 13 & 0 & 1 & 1 & 0 & 0 & 1 & 16 & 0,09 \\
\hline Pró-Reitorias & 376 & 2 & 6 & 1 & 0 & 20 & 27 & 432 & 2,34 \\
\hline Secretarias & 156 & 2 & 3 & 0 & 1 & 2 & 54 & 218 & 1,18 \\
\hline Sem dados & 1 & 0 & 0 & 0 & 0 & 0 & 0 & 1 & 0,01 \\
\hline Total & 15545 & 470 & 423 & 348 & 143 & 478 & 1091 & 18498 & 100,00 \\
\hline
\end{tabular}

Tabela 1 - Setores da UFSC responsáveis pelos projetos de extensão realizados em diferentes mesorregiões de SC - 2008 a 2013.

Fonte: Setic/UFSC, 2015.

\footnotetext{
${ }^{3}$ Os Centros de Ensino atualmente existentes na UFSC são: Centro de Ciências Agrárias (CCA); Centro de Ciências Biológicas (CCB); Centro de Ciências da Educação (CED); Centro de Ciências Físicas e Matemáticas (CFM); Centro de Ciências Jurídicas (CCJ); Centro de Ciências da Saúde (CCS); Centro de Ciências da Comunicação e Expressão (CCE); Centro de Desportos (CDS); Centro de Ciências de Filosofia e Ciências Humanas (CFH); Centro Socioeconômico (CSE); Centro Tecnológico (CTC). A UFSC possui também um Colégio de Aplicação vinculado ao CED.
} 
Extensão universitária: entre o continuismo e a utopia

Na sequência é possível constatar (Tabela 2) um detalhamento do número de projetos realizados pelos diferentes centros da UFSC nas diferentes mesorregiões do Estado de Santa Catarina (como já explicado, a categoria "outros" refere-se a projetos realizados em outros estados ou países, cujo número, estranhamente, é superior ao de muitas regiões de Santa Catarina).

\begin{tabular}{|c|c|c|c|c|c|c|c|c|}
\hline \multirow[b]{2}{*}{ CENTRO } & \multicolumn{7}{|c|}{ MESORREGIÃO } & \multirow[b]{2}{*}{ TOTAL } \\
\hline & $\begin{array}{l}\text { Grande } \\
\text { Fpolis }\end{array}$ & Norte & $\begin{array}{l}\text { Vale } \\
\text { do } \\
\text { Itajaí }\end{array}$ & Oeste & Serrana & Sul & Outros & \\
\hline CCA & 578 & 36 & 24 & 53 & 23 & 15 & 128 & 857 \\
\hline CCB & 1672 & 17 & 32 & 12 & 6 & 21 & 114 & 1874 \\
\hline CCS & 2099 & 31 & 55 & 46 & 14 & 35 & 144 & 2424 \\
\hline CFM & 585 & 11 & 7 & 9 & 2 & 6 & 61 & 681 \\
\hline CCJ & 563 & 1 & 13 & 10 & 1 & 6 & 26 & 620 \\
\hline CCE & 1963 & 27 & 42 & 38 & 3 & 27 & 54 & 2154 \\
\hline CDS & 488 & 0 & 1 & 1 & 1 & 3 & 35 & 529 \\
\hline CED & 2058 & 12 & 30 & 30 & 6 & 38 & 124 & 2298 \\
\hline $\mathrm{CFH}$ & 1780 & 18 & 62 & 30 & 3 & 23 & 103 & 2019 \\
\hline CSE & 1062 & 31 & 50 & 42 & 5 & 32 & 39 & 1261 \\
\hline CTC & 2096 & 137 & 94 & 73 & 10 & 97 & 156 & 2663 \\
\hline TOTAL & 14944 & 321 & 410 & 344 & 74 & 303 & 984 & 17380 \\
\hline
\end{tabular}

Tabela 2 - Número de projetos realizados pelos diferentes centros da UFSC nas diferentes mesorregiões do Estado de SC- 2008 a 2013.

Fonte: Setic/UFSC, 2015.

Pela Tabela 2, constata-se que a já mencionada concentração na Região da Grande Florianópolis pode ser percebida também na atuação de cada Centro de Ensino. Todavia, comparativamente ao número total de projetos de cada Centro de Ensino, pode ser observada uma relativa descentralização de atuação de alguns centros, como é o caso do Centro de Ciências Agrárias (explicável pela localização do setor agrário no Estado), o Centro Tecnológico (relativo a espacialização do complexo industrial catarinense).

\section{d) Áreas temas dos projetos de Extensão e as Mesorregiões de atuação}

Como observação complementar, procurou-se identificar as áreas temas dos projetos de Extensão da UFSC, relacionando-as com as Mesorregiões, no sentido de procurar verificar a existência algum tipo de interdisciplinaridade ou de atuação intersetorial.

Infelizmente, a maioria dos projetos não deram subsídios para este tipo de análise, como pode ser verificado na Figura 5. 
Extensão universitária: entre o continuismo e a utopia

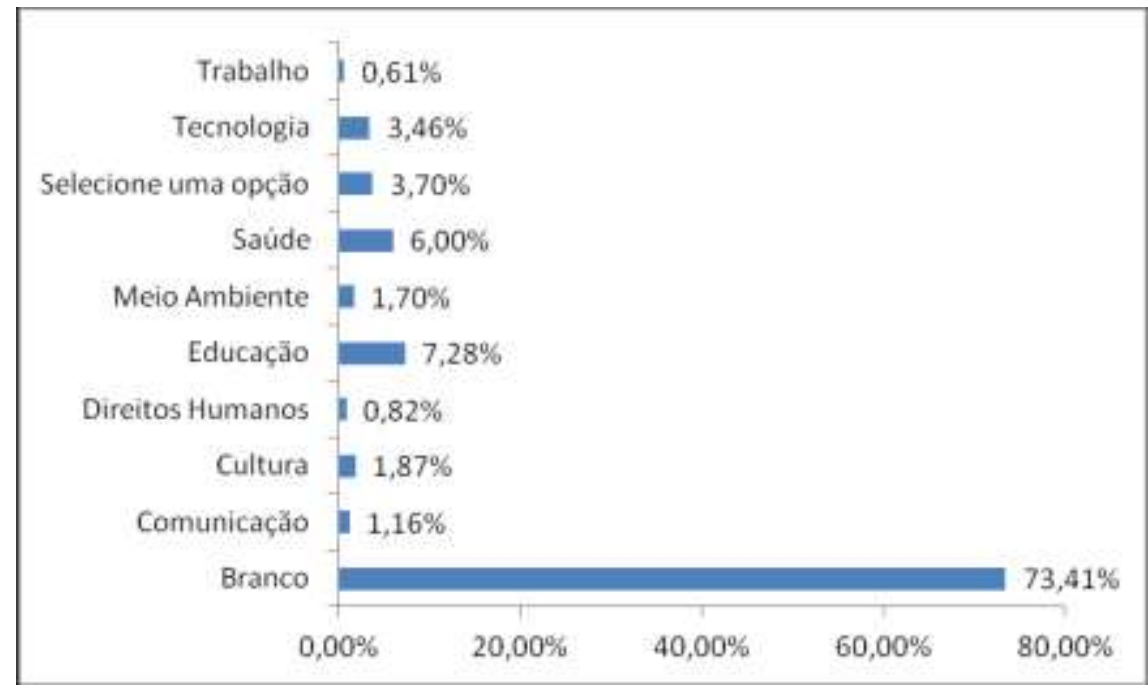

Figura 5 - Percentual das diferentes áreas/tema do conhecimento que envolveram os projetos de extensão da UFSC- 2008 a 2013 Fonte: Setic/UFSC, 2015.

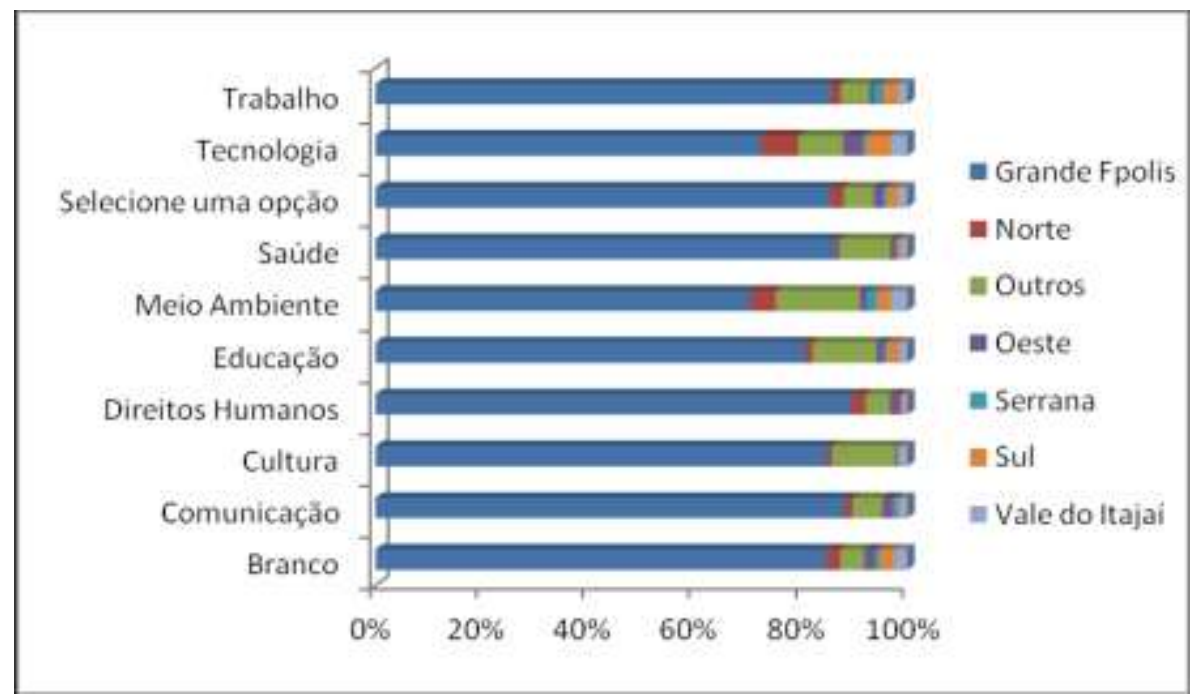

Figura 6 - Percentual das mesorregiões onde os projetos de extensão foram executados, nas diferentes áreas/tema do conhecimento- 2008 a 2013

Fonte: Setic/UFSC, 2015. 


\begin{tabular}{|c|c|c|c|c|c|c|c|c|}
\hline \multirow[b]{2}{*}{ Áreas Temas } & \multicolumn{8}{|c|}{ Mesorregião } \\
\hline & $\begin{array}{c}\text { Grande } \\
\text { Fpolis }\end{array}$ & Norte & Outros & Oeste & Serrana & Sul & $\begin{array}{l}\text { Vale } \\
\text { do } \\
\text { Itajá }\end{array}$ & Total \\
\hline "Em branco" & 11511 & 356 & 613 & 271 & 110 & 383 & 335 & 13579 \\
\hline Comunicação & 189 & 3 & 12 & 4 & 2 & 1 & 3 & 214 \\
\hline Cultura & 293 & 3 & 41 & 1 & 1 & 1 & 5 & 345 \\
\hline Direitos Humanos & 136 & 4 & 7 & 3 & 0 & 1 & 1 & 152 \\
\hline Educação & 1088 & 19 & 162 & 17 & 10 & 29 & 22 & 1347 \\
\hline Meio Ambiente & 222 & 15 & 50 & 4 & 6 & 8 & 10 & 315 \\
\hline Saúde & 961 & 6 & 107 & 12 & 3 & 9 & 12 & 1110 \\
\hline $\begin{array}{l}\text { "Opção não } \\
\text { escolhida"" }\end{array}$ & 585 & 17 & 39 & 12 & 5 & 13 & 13 & 684 \\
\hline Tecnologia & 464 & 45 & 54 & 23 & 4 & 30 & 20 & 640 \\
\hline Trabalho & 96 & 2 & 6 & 1 & 2 & 3 & 2 & 112 \\
\hline
\end{tabular}

Tabela 3 - Número de projetos realizados nas diferentes dimensões do conhecimento e executados nas diferentes mesorregiões de SC- 20082013. Fonte: Setic/UFSC, 2015.

Para complementar esta análise, verificou-se a distribuição geral dos projetos de Extensão da UFSC, por município, excluindo-se Florianópolis, a capital do estado de Santa Catarina, onde está localizada a sede da UFSC e sua maior quantidade de cursos de graduação e pós-graduação. A Tabela 4 expressa esta realidade.

Percebe-se uma concentração nas regiões dos Campi Joinville, Curitibanos e Araranguá, bem como em alguns polos industriais, como Blumenau, Chapecó, Criciúma, Itajaí e São José. 


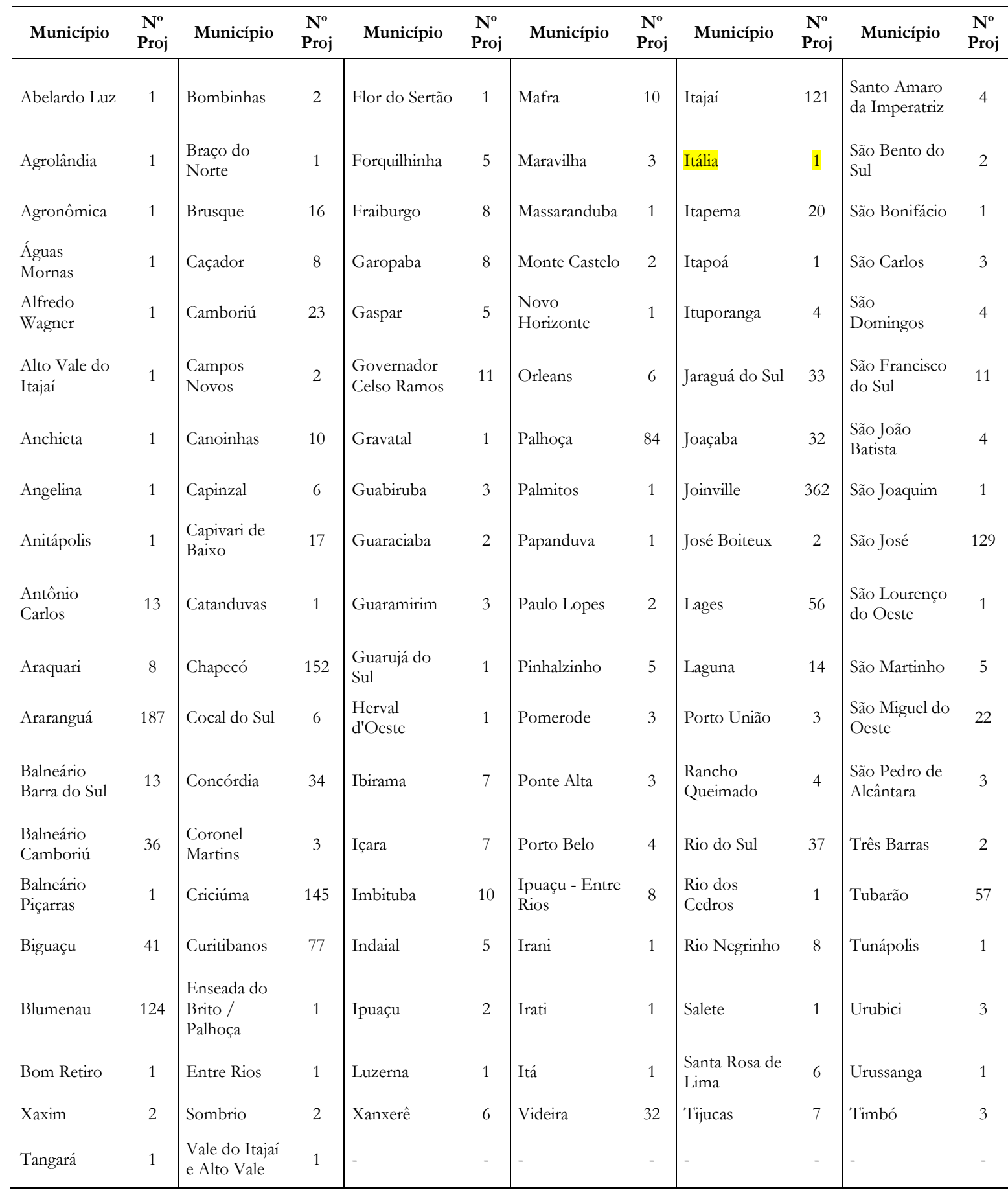

Tabela 4 - Número de Projetos de Extensão da UFSC, por município do estado de Santa Catarina, excluindo-se Florianópolis - 2008 a 2013.

Fonte: Setic/UFSC, 2015.

Se retirarmos, para efeito de uma análise complementar, o Município de Florianópolis e os projetos realizados em outros estados e países, podemos constatar mais ainda o sentido da concentração dos projetos de Extensão (ver Tabela 5). Dos anteriores 18.498 projetos de Extensão, agora nesta condição restam apenas 2.170. 


\begin{tabular}{|c|c|c|c|c|c|c|c|}
\hline \multirow[b]{2}{*}{ Área Tema } & \multicolumn{6}{|c|}{ Mesorregião } & \multirow[b]{2}{*}{ Total } \\
\hline & $\begin{array}{c}\text { Grande } \\
\text { Fpolis }\end{array}$ & Norte & Oeste & Serrana & Sul & $\begin{array}{c}\text { Vale do } \\
\text { Itajaí }\end{array}$ & \\
\hline Branco & 218 & 356 & 271 & 110 & 383 & 335 & 1673 \\
\hline CFH & 0 & 0 & 1 & 0 & 0 & 0 & 1 \\
\hline Comunicação & 3 & 3 & 4 & 2 & 1 & 3 & 16 \\
\hline Cultura & 10 & 3 & 1 & 1 & 1 & 5 & 21 \\
\hline Direitos Humanos & 1 & 4 & 3 & 0 & 1 & 1 & 10 \\
\hline Educação & 20 & 19 & 16 & 10 & 29 & 22 & 116 \\
\hline Meio Ambiente & 10 & 15 & 4 & 6 & 8 & 10 & 53 \\
\hline Saúde & 18 & 6 & 12 & 3 & 9 & 12 & 60 \\
\hline $\begin{array}{l}\text { Opção } \\
\text { escolhida }\end{array}$ & 6 & 17 & 12 & 5 & 13 & 13 & 66 \\
\hline Tecnologia & 13 & 45 & 23 & 4 & 30 & 20 & 135 \\
\hline Trabalho & 9 & 2 & 1 & 2 & 3 & 2 & 19 \\
\hline Total & 308 & 470 & 348 & 143 & 478 & 423 & 2170 \\
\hline$\%$ Total & 14,19 & 21,66 & 16,04 & 6,59 & 22,03 & 19,49 & 100,00 \\
\hline
\end{tabular}

Tabela 5 - Eventos de Projetos de Extensão da UFSC por área tema no estado de Santa Catarina, excetuando o município de Florianópolis e projetos realizados em outros estados e países- 2008 a 2013 Fonte: Setic/UFSC, 2015.

Na Tabela 6, pode-se observar a distribuição dos projetos de Extensão por mesorregião, excetuando o município de Florianópolis, categorizados por área físico-institucional da UFSC, sendo possível constatar a lógica da concentração em algumas mesorregiões em função de terem polos de Campi da UFSC. Contudo, por outro lado, fica evidente a falta de cobertura de algumas dimensões de conhecimento em outras importantes mesorregiões do Estado de Santa Catarina. Isto, seguramente, indica também falta de integração interdisciplinar e intersetorial dos projetos.

\begin{tabular}{|c|c|c|c|c|c|c|c|}
\hline \multirow[b]{2}{*}{ Centro } & \multicolumn{6}{|c|}{ Mesorregião } & \multirow[b]{2}{*}{ Total } \\
\hline & $\begin{array}{c}\text { Grande } \\
\text { Fpolis }\end{array}$ & Norte & Oeste & Serrana & Sul & $\begin{array}{c}\text { Vale do } \\
\text { Itajaí }\end{array}$ & \\
\hline Campus de Araranguá & 0 & 2 & 0 & 0 & 150 & 2 & 154 \\
\hline Campus de Curitibanos & 0 & 0 & 2 & 68 & 1 & 0 & 71 \\
\hline Campus de Joinville & 0 & 143 & 0 & 0 & 2 & 1 & 146 \\
\hline Centro de Ciências Agrárias & 18 & 36 & 53 & 23 & 15 & 24 & 169 \\
\hline Centro de Ciências Biológicas & 27 & 17 & 12 & 6 & 21 & 32 & 115 \\
\hline Centro de Ciências da Saúde & 20 & 31 & 46 & 14 & 35 & 55 & 201 \\
\hline Centro de Ciências Físicas e Matemáticas & 3 & 11 & 9 & 2 & 6 & 7 & 38 \\
\hline Centro de Ciências Jurídicas & 6 & 1 & 10 & 1 & 6 & 13 & 37 \\
\hline Centro de Comunicação e Expressão & 41 & 27 & 38 & 3 & 27 & 42 & 178 \\
\hline Centro de Desportos & 4 & 0 & 1 & 1 & 3 & 1 & 10 \\
\hline Centro de Educação & 66 & 12 & 30 & 6 & 38 & 30 & 182 \\
\hline
\end{tabular}




\begin{tabular}{|c|c|c|c|c|c|c|c|}
\hline Centro de Filosofia e Ciências Humanas & 40 & 15 & 27 & 3 & 19 & 56 & 160 \\
\hline Centro de Filosofia e Ciências Humanas & 3 & 3 & 2 & 0 & 4 & 6 & 18 \\
\hline Centro Socioeconômico & 20 & 31 & 42 & 5 & 32 & 50 & 180 \\
\hline Centro Tecnológico & 53 & 137 & 73 & 10 & 97 & 94 & 464 \\
\hline Colégio de Aplicação & 1 & 0 & 1 & 0 & 0 & 1 & 3 \\
\hline Gabinete do Reitor & 0 & 0 & 0 & 0 & 1 & 0 & 1 \\
\hline “Ipuaçu” (*) & 0 & 0 & 1 & 0 & 0 & 0 & 1 \\
\hline Pró-Reitoria de Cultura e Extensão & 0 & 0 & 0 & 0 & 0 & 2 & 2 \\
\hline Pró-Reitoria de Ensino de Graduação & 0 & 1 & 0 & 0 & 0 & 4 & 5 \\
\hline Pró-Reitoria de Infraestrutura & 0 & 1 & 0 & 0 & 19 & 0 & 20 \\
\hline Pró-Reitoria de Pesquisa e Extensão & 2 & 0 & 1 & 0 & 0 & 0 & 3 \\
\hline Secretaria de Cultura & 1 & 0 & 0 & 0 & 1 & 0 & 2 \\
\hline Secretaria de Cultura e Arte & 3 & 2 & 0 & 1 & 1 & 3 & 10 \\
\hline Total & 308 & 470 & 348 & 143 & 478 & 423 & 2170 \\
\hline$\%$ total & 14,19 & 21,66 & 16,04 & 6,59 & 22,03 & 19,49 & $\begin{array}{r}100,0 \\
0\end{array}$ \\
\hline
\end{tabular}

(*) "Ipuaçu" - é um município do Oeste de Santa Catarina, mas estranhamente foi registrado como se fosse um Centro de Ensino ou área da estrutura da UFSC, ao qual estaria ligado um projeto de Extensão.

Tabela 6 - Distribuição dos projetos de Extensão por mesoregião (excetuando Florianópolis e "outros”), por área físico-institucional da UFSC Fonte: Setic/UFSC, 2015.

É interessante observar, na Figura 7, a seguir, o crescimento do número de projetos de Extensão da UFSC no período de 2008 a 2012 e seu decréscimo no período de 2013, retomando praticamente o mesmo número de 2008. Somente uma análise mais apurada poderia dar indicadores que expliquem esta diminuição.

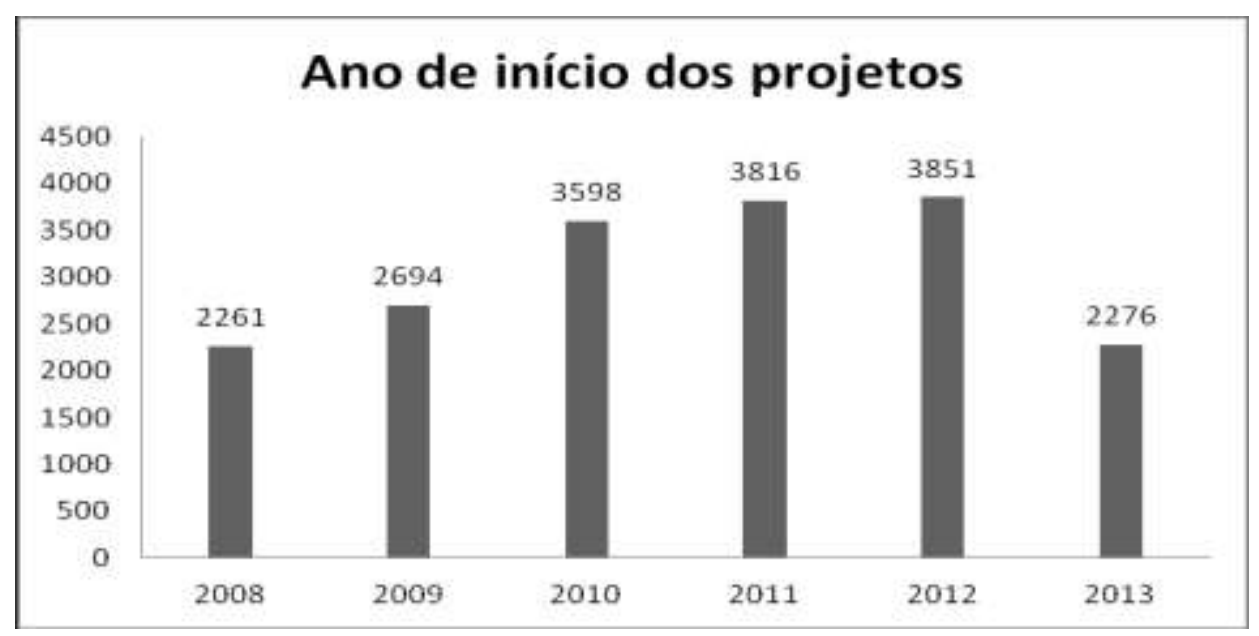

Figura 7 - Ano de início dos projetos de Extensão da UFSC - Período 2008 a 2013 Fonte: Setic/UFSC, 2015. 
Extensão universitária: entre o continuismo e a utopia

Nesta Tabela 7, a seguir, surpreende o número de projetos por Coordenador nos casos das categorias de "mais de 11", o que pode indicar certa superficialidade da dimensão Extensão, pelo fato de um/a mesma/o coordenador/a ter sob sua coordenação um grande número de projetos. Mas isso também pode resultar da forma de registro, porque muitas atividades, como já mencionado, são classificadas como "Extensão", quando deveriam estar categorizadas como Pesquisa, Ensino ou mesmo outras atividades.

\begin{tabular}{lcccc}
\hline Categoria & Frequência & $\begin{array}{c}\text { Percentual } \\
\mathbf{( \% )}\end{array}$ & $\begin{array}{c}\text { Frequência } \\
\text { acumulada }\end{array}$ & $\begin{array}{c}\text { Percentual } \\
\text { acumulado (\%) }\end{array}$ \\
\hline 1 a 5 & 1065 & 43,24 & 1065 & 43,24 \\
6 a 10 & 840 & 34,10 & 1905 & 77,34 \\
11 a 20 & 337 & 13,68 & 2242 & 91,03 \\
21 a 50 & 192 & 7,80 & 2434 & 98,82 \\
Acima de 51 & 29 & 1,18 & 2463 & 100,00 \\
\hline
\end{tabular}

Tabela 7 - Número de projetos de Extensão da UFSC por coordenador, período de 2008 a 2013 Fonte: Setic/UFSC, 2015.

\section{CONCLUSÕES E RECOMENDAÇÕES PRELIMINARES}

Como explicitado anteriormente, este trabalho precisa ser discutido coletivamente dentro da Universidade Federal de Santa Catarina, no sentido de refinar sua análise, principalmente pela incorporação de novos dados, os quais não é possível resgatar através do atual sistema de informação disponível.

De maneira alguma este trabalho tem a intenção de "avaliar" projetos em execução, mas sim poder contribuir para um debate desafiador. Neste sentido, são apresentadas, também preliminarmente, algumas conclusões e recomendações que podem ser importantes indicadores de discussão e aprofundamento, no sentido de se buscar uma política de Extensão Universitária mais consistente, dinâmica, contemporânea e perfeitamente articulada com as necessidades concretas do coletivo da Sociedade que compõe o espaço geoeducacional da UFSC, ou seja, o estado de Santa Catarina como um todo, principalmente as áreas com menor Índice de Desenvolvimento Humano:

1. Pelos registros disponíveis, o sistema de Extensão Universitária da UFSC reserva para a "Extensão" muitas atividades que não têm espaço institucional em outras formas de registro (por exemplo, em Pesquisa e Ensino ou outras atividades).

Por exemplo, fica difícil entender que atividades como "participação em bancas de tese e/ou dissertação" sejam registradas como "Extensão". Essas atividades deveriam ser entendidas como Pesquisa, pois se referem à última etapa (avaliação e homologação) de uma pesquisa 
Extensão universitária: entre o continuismo e a utopia

metodologicamente concebida. Igualmente também deveriam ser registradas como Pesquisa, não Extensão, atividades como "parecerista em artigo científico/ou de capítulo de livro" ou mesmo “participação em Conselho Editorial”, produção de livros e outras publicações, ou atividades similares.

Constatou-se, inclusive, o registro de "participação em bancas de TCC ou Monografias" como atividade de Extensão. Essas atividades devem ser consideradas como o segmento final do processo de Ensino.

Recomenda-se que se analisem, com novos critérios, todas as formas de Extensão e se criem novas categorias de registro institucional nas atividades de Ensino e Pesquisa. Ou seja, o fundamental seria construir claramente um novo conceito de Extensão e, a partir daí, criarem-se novos critérios de registro adequados ao novo conceito. Para tanto, o Fórum dos Pró-Reitores de Extensão formulou excelente documento (FÓRUM DOS PRÓ-REITORES DE EXTENSÃO DE UNIVERSIDADES PÚBLICAS BRASILEIRAS, 2013) caracterizando uma política realmente inovadora para o País.

2. Recomenda-se melhor controle no registro das informações dos projetos de Extensão, na medida em que é notória a falta de cuidado quanto a estes registros no sistema, o que impede uma análise mais criteriosa. Referimo-nos às denominações dos projetos, áreas assistidas, temas envolvidos, datas de início e conclusão dos projetos, etc.

3. A constatação da grande concentração dos projetos da UFSC na região da Grande Florianópolis, e principalmente, no município de Florianópolis, é preocupante, pois pode indicar que a UFSC está “de costas" para o restante do estado de Santa Catarina.

4. Apesar de o intervalo temporal analisado envolver praticamente apenas seis anos, percebe-se que a UFSC faz um esforço considerável em Extensão Universitária. A grande pergunta que se coloca é "Que resultados efetivos têm sido alcançados?”. Outra pergunta fundamental, quando o país tem políticas de busca do resgate da dívida social com segmentos historicamente desprivilegiados, é "As populações mais carentes e as regiões de menor IDH têm sido contempladas pelas ações de Extensão da UFSC?”. Se a resposta for positiva, surge outra pergunta: “A complexidade da problemática destas populações/regiões tem sido encarada pelos projetos de Extensão da UFSC de uma maneira interdisciplinar e intersetorial"?

Não foi possível analisar cada projeto ou grupos de projetos com atuação numa mesma área geográfica. No entanto, permanece a hipótese que na sua grande maioria, estes projetos são resultados de ações individuais de professores, ou grupos temáticos restritos e pouco tem de ações interdisciplinares. 
Extensão universitária: entre o continuismo e a utopia

Também não foi possível (nem era objetivo deste trabalho nesta fase) analisar o reflexo dos projetos de Extensão nas ações de Ensino e na sua relação com a Pesquisa, dentro da perspectiva da indissociabilidade destas três dimensões. No entanto, ratifica-se como fundamental esta relação de indissociabilidade.

5. A própria definição territorial de cada projeto, construída a partir de iniciativas particulares de professores ou grupos temáticos, pode indicar uma enorme dispersão de esforços setoriais, sem o devido retorno à Sociedade como um todo e o beneficiamento de grupos de interesse específicos. Também verifica-se a falta de priorização de municípios com IDH mais baixo.

6. Como proposta finalística, sugere-se que a UFSC, para maior consistência de sua ação de Extensão, a partir da Pró-Reitoria de Extensão, implemente alguns projetos piloto de Extensão Universitária, que tenham algumas características básicas e fundamentais:

- Estabelecer áreas piloto a partir de territórios/zonas mais carentes e com os IDH mais baixos do Estado.

- Realizar um levantamento participativo sócio-econômico-ambiental e de gestão pública (envolvendo equipes de professores de diversos setores/Centros de Ensino, estudantes, comunidades envolvidas, entidades municipais/regionais desses territórios) de maneira a obter um quadro inicial das situações reais, problemas, potencialidades, prioridades e planos de trabalho/responsabilidades.

É importante mencionar que o Centro de Ciências Agrárias implementa uma disciplina obrigatória para os cursos de Agronomia e Zootecnia, denominada "Vivência em Agricultura Familiar", na qual estudantes vivem por 21 dias com famílias de agricultores familiares para trabalhar e conhecer sua "lógica de trabalho e decisão" (MUSSOI, 1996). Essa atividade, a cada semestre, é realizada em um município diferente, o que pode ser uma excelente forma de "chegar aos municípios". A cada semestre, as municipalidades fazem demandas à Universidade, no sentido de maior apoio e assessoria.

- É fundamental que este grupo de análise e de atuação em extensão seja realmente interdisciplinar e intersetorial, contendo especialistas em Gestão Pública, Ciências Agrárias (dentro de suas diversas especialidades), Saúde, Educação, Economia, Engenharias, Comunicação, Ciências Humanas, Ciências Jurídicas, Desportos, etc.

- É também fundamental que este grupo de professores da UFSC tenha uma capacitação, como preparo metodológico-pedagógico especial, no sentido de qualificar sua aproximação à comunidade e seus procedimentos de intervenção interdisciplinar. 
Extensão universitária: entre o continuismo e a utopia

\section{REFERÊNCIAS}

BORCHARDT, I. Diagnóstico da exclusão social em Santa Catarina: mapa da fome. Florianópolis: SDS/Instituto Cepa/SC, 2003.

FÓRUM DOS PRÓ-REITORES DE EXTENSÃO DE UNIVERSIDADES PÚBLICAS BRASILEIRAS. Politica Nacional de Extensão Universitária. Porto Alegre: Editora UFRGS, 2013.

IBGE-Instituto Brasileiro de Geografia e Estatística. Perfil dos Municípios Brasileiros. www.ibge.gov.br/home/estatistica/economia/perfilmunic/2009. Acesso em 20/08/2013.

JAPIASSU, H.; MARCONDES, D. Dicionário básico de filosofia. Rio de Janeiro: Zahar, 2001.

KOCKELMANS, J. J. (Ed.). Interdisplinarity and higher education. University Park/London: Pennsylvania State University, 1979.

MUSSOI, E. M. Living and working with peasants: learning about sustainability and agricultural systems starting from the university. System-Oriented Research - Second European Symposium. Granada, Spain. March, 27-29, 1996. Proceedings... Disponível em: http://ifsa.boku.ac.at/cms/fileadmin/Proceeding1996/1996 WS06 52 Mussoi.pdf. Acesso em: $15 / 08 / 2013$.

RAYNAUT, C. Interdisciplinaridade: mundo contemporâneo, complexidade e desafios à produção e à aplicação de conhecimentos. In: PHILIPPI JUNIOR, A.; SILVA NETO, A. J. (Eds.). Interdisciplinaridade em ciência, tecnologia \& inovação. Barueri: Manole, 2011.

SANTANDREU, A.; MERZTHAL, G. Identificación participativa y análisis de actores de la agricultura urbana. Lima, Peru: IPES, 2007. 